perspectivas

a debate EI marco legal para la protección del patrimonio paleontológico. ¿Qué pasa en tu comunidad?

| coordina Eloísa Bernáldez Sánchez

\title{
Patrimonio paleontológico en Colombia: ¿esperanzas en el horizonte?
}

\author{
Sandra Patricia Maya Ealo | abogada egresada de la Universidad EAFIT \\ Harold Fernando Jiménez Velandia | geólogo egresado de la Universidad EAFIT
}

URL de la contribución <www.iaph.es/revistaph/index.php/revistaph/article/view/4163>

En los últimos 15 años, numerosos hallazgos están cambiando la percepción de Colombia, ubicándola como una región con un alto potencial paleontológico. Es el caso del Padillasaurus leivaensis, la primera especie acuñada de un dinosaurio en Colombia y el único Brachiosauridae conocido en Sudamérica (CARBALLIDO; POL, PARRA RUGE et ál., 2015); Desmatochelys padillai, considerada como la especie más antigua de tortuga marina (CADENA; PARHAM, 2015); Telamonocarcinus Antiquus, el cangrejo que cambia la hipótesis del origen de este grupo (LUQUE, 2015); Titanoboa cerrejonensis, la serpiente más grande que habitó el planeta hasta el momento (HEAD; BLOCH; HASTINGS et ál., 2009; JARAMILLO; OVIEDO, 2017); los primeros registros de la selva tropical (WING; HERRERA; JARAMILLO et ál., 2009; JARAMILLO; OVIEDO, 2017). Y, con los nuevos descubrimientos, el interés por proteger el patrimonio paleontológico ha empezado a cambiar la legislación colombiana.

Las normas para la protección del patrimonio paleontológico en Colombia permiten determinar los procedimientos de protección con el fin de evitar su destrucción por desconocimiento o falta de interés de los particulares y el robo o exportación ilícita por parte de nacionales y extranjeros; establece procedimientos para la creación de planes de trabajo y asignación de competencias y obligaciones por parte de entes privados y públicos, además de ofrecer claridad y seguridad para los profesionales durante sus investigaciones (MAYA, 2016).

Actualmente, el país cuenta con normas para la protección de elementos paleontológicos. No obstante, dichas normas fueron establecidas pensando en la protección del patrimonio cultural, histórico y arqueológico (MAYA,
2016). Un estudio normativo ayuda a dilucidar que el patrimonio paleontológico solo es nombrado para supeditar su protección a los términos en que se protege el patrimonio arqueológico, como refleja el texto del artículo 6 de la Ley 397 de 1997 -Ley General de Culturaque expresa que "para la preservación de los bienes integrantes del patrimonio paleontológico se aplicarán los mismos instrumentos establecidos para el patrimonio arqueológico" (art. 6 Ley 397 de agosto 7 de 1997) (MAYA, 2016). La normatividad no es clara y se presta para confusión entre el área de estudio de la arqueología y el de la paleontología, lo cual indicaría que el legislador solo se estaba enfocando a los fósiles de homínidos, olvidando al resto de organismos (MAYA, 2016).

De otro lado, al Servicio Geológico de Colombia (SGC) -antes Ingeominas-, por medio del Decreto 4131 del 3 de noviembre de 2011, le fueron asignadas funciones investigativas sobre los recursos del subsuelo, las cuales son enumeradas en el artículo 4 de este decreto, entre ellas: "9. Identificar, evaluar y establecer zonas de protección que, en razón de la presencia de patrimonio geológico o paleontológico del país, puedan considerarse áreas protegidas" (art. 4.9 Decreto 4131 del 3 de noviembre de 2011). De lo que se desprende que tiene la responsabilidad del patrimonio paleontológico inmueble del país. A lo cual se le suman los numerales 3,4 y 5 del artículo 2 del Decreto 2703 del 22 de noviembre de 2013 donde se le asignan funciones al Director General del Servicio Geológico, para la custodia del patrimonio paleontológico.

En este mismo sentido, la función de administración del Museo Geológico Nacional José Royo y Gómez se 
a debate El marco legal para la protección del patrimonio paleontológico. ¿Qué pasa en tu comunidad?
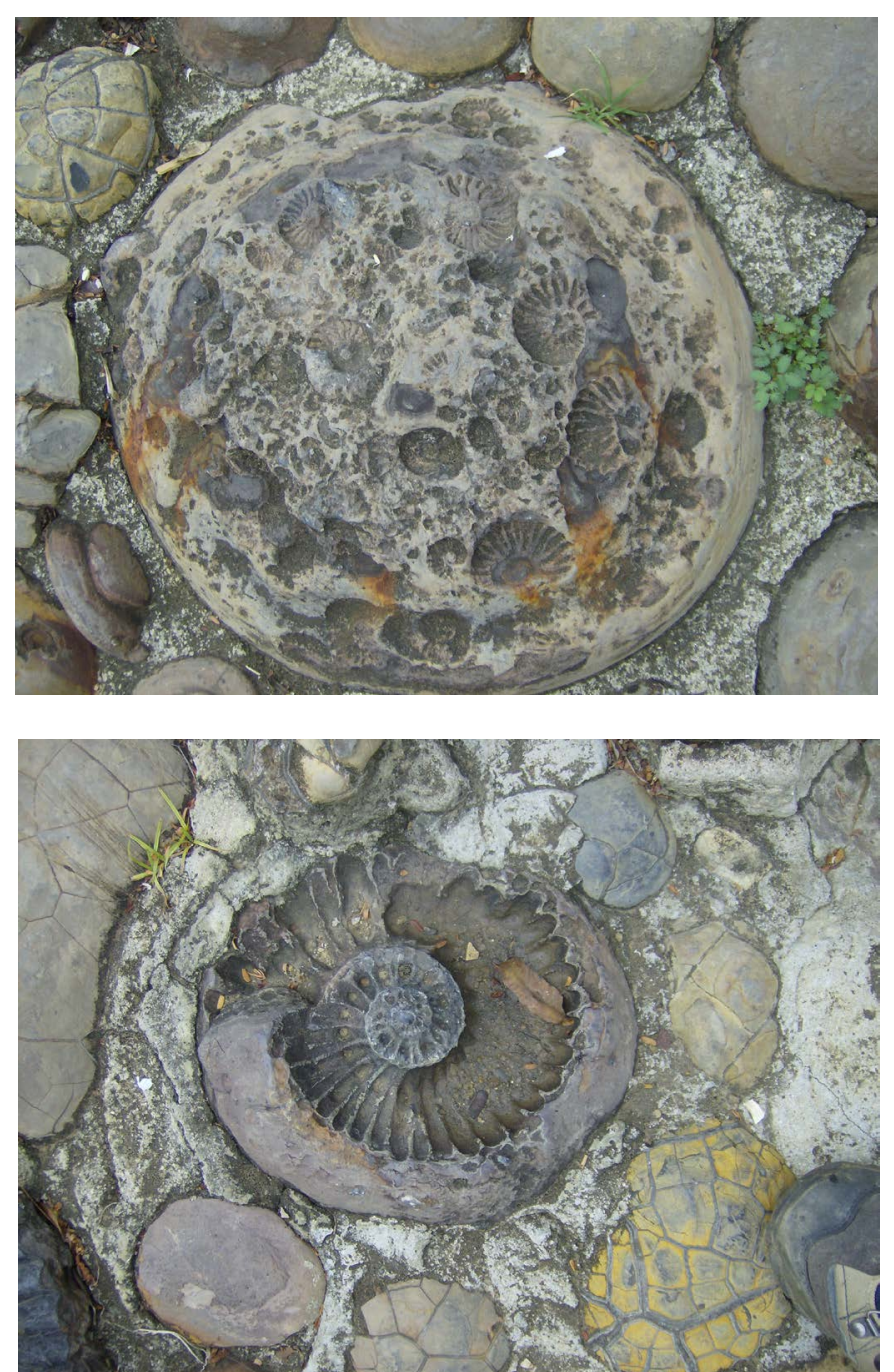

Concreciones con moldes externos de amonitas. Parque de Guane, Santander (Colombia), 2009 | fotos Harold Fernando Jiménez Velandia

mantiene con en el artículo 4.6 del Decreto 4131 del 3 de noviembre de 2011 (ESPINOZA, 2018). "El SGC por intermedio del Museo Geológico Nacional José Royo y Gómez es el repositorio oficial de las colecciones científicas paleontológicas de Colombia" (SGC, 2014: 30). Así las cosas, el SGC bien podría ser, a su vez, el encargado de la administración y protección de las colecciones científicas paleontológicas del país, al igual que de los museos que las contienen (MAYA, 2016). En otras palabras, el responsable del patrimonio paleontológico mueble.
Lo anterior tiene sentido en tanto que el Decreto 4131 del 3 de noviembre de 2011 bien podría cambiar la competencia de administrar el patrimonio paleontológico. En primera instancia, debido a su jerarquía como decreto con fuerza de ley, dictado por las facultades extraordinarias del ejecutivo de acuerdo al art. 150.10 de la Constitución de 1991, concedidas a aquel por el Congreso por medio del artículo 18 literal e de la Ley 1444 de mayo 4 de 2011. Y segundo, por la derogación tácita de las normas que le sean contrarias (art. 18, Decreto 4131 del 3 de noviembre de 2011) (MAYA, 2016).

Como parte de sus funciones en la protección del patrimonio paleontológico de Colombia, el SGC se centra en la repatriación de los ejemplares entregados en calidad de préstamo y no han sido devueltos o que se encuentran de forma ilegal en diferentes colecciones de todo el mundo. Añadido a esto, también se encuentra en la tarea de instaurar un decreto para el establecimiento de técnicas o métodos de recolección del material paleontológico (BUSTAMANTE, 2018; TABORDA; 2018; FOG, 2018).

Aunque en materia de legislación se están haciendo grandes cambios, todavía contamos con muchos inconvenientes. La baja disponibilidad de empleo para los pocos profesionales especializados en paleontología, la escasa formación de especialidades de paleontología en centros de educación superior en el país, los pocos espacios físicos (museos, universidades, etc.) adecuados para el almacenamiento y protección del material, las inadecuadas edificaciones (salones comunales, viviendas, etc.) empleadas como museos, la pobre calidad de las exhibiciones (reconstrucciones, iluminación, vitrinas, paleoilustraciones, paneles de información, dioramas, incorporación de la tecnología, personal o guías certificados, etc.) y el limitado espacio en los medios de comunicación (prensa, radio, televisión, aplicaciones tecnológicas, documentales, libros, etc.) para la divulgación y socialización de la paleontología como ciencia y patrimonio exponen un gran recorrido que debe hacer la nación y las entidades para la protección del patrimonio. 
a debate El marco legal para la protección del patrimonio paleontológico. ¿Qué pasa en tu comunidad?

\section{BIBLIOGRAFÍA}

- Bustamante heRNÁNDEZ, N. (2018) Así fue como Colombia recuperó un cráneo perdido hace 66 años. El Tiempo [en línea] 06 de abril 2018 <http://www.eltiempo.com/vida/ ciencia/encuentran-craneo-de-plesiosaurio-que-pertenecia-acolombia-en-estados-unidos-201656> [Consulta: 12/04/2018]

- CADENA, E. A.; PARHAM, J. F. (2015) Oldest known marine turtle? A new protostegid from the Lower Cretaceous of Colombia. PaleoBios [en línea] <https://escholarship.org/uc/ item/147611bv> 32(1), 2015, pp. 1-42 [Consulta: 12/04/2018]

- CARBALLIDO, J. L.; POL, D.; PARRA RUGE, M. L.; PADILLA BERNAL, S.; PÁRAMO-FONSECA, M. E.; ETAYO-SERNA, F. (2015) A new Early Cretaceous brachiosaurid (Dinosauria, Neosauropoda) from northwestern Gondwana (Villa de Leiva, Colombia). Journal of Vertebrate Paleontology, 35(5), DOI: 10.1080/02724634.2015.980505

- ESPINOZA, A. (2018) Breve Historia del Servicio Geológico Colombiano. En Servicio Geológico Colombiano [en línea]. Bogotá: Servicio Geológico Colombiano, 2016-2017<https:// www2.sgc.gov.co/Nosotros/AcercaDelSgc/Paginas/Historia. aspx> [Consulta: 12/04/2018]

- FOG CORRADINE, L. (2018) De cómo el plesiosaurio de Villa de Leyva encontró su cabeza. Revista Semana [en línea] $<$ http://www.semana.com/educacion/articulo/servicio-geo logico-colombiano-recupero-el-plesiosaurio-encontradoen-villa-de-leyva/562660> 6 de abril de 2018 [Consulta: 13/04/2018]

- HEAD, J. J.; BLOCH, J. I.; HASTINGS, A. K.; BOURQUE, J. R.; CADENA, E. A.; HERRERA, F. A.; POLLY, P.D.; JARAMILLO, C. A. (2009) Giant boid snake from the Palaeocene neotropics reveals hotter past equatorial temperatures. Nature, 457(7230), 715

- JARAMILlo, C.; OVIEDO, L. H. (ed.) 2017 Hace tiempo. Un viaje paleontológico ilustrado por Colombia. Bogotá: Instituto Alexander von Humboldt e Instituto Smithsonian de Investigaciones Tropicales, 2017

- LUQUE, J. (2015) The oldest higher true crabs (Crustacea: Decapoda: Brachyura): insights from the Early Cretaceous of the Americas. Palaeontology, 58(2), 2015, pp. 251-263

- MAYA EALO, S. P. (2016) Patrimonio Paleontológico de Colombia: Concepto, Importancia, estudio normativo y perspectivas de regulación. Proyecto de grado inédito. Escuela de Derecho. Universidad EAFIT. Colombia, Medellín [disponible en línea] <https://repository.eafit.edu.co/handle/10784/11223> [Consulta: 13/04/2018]

- PLAN Estratégico del Conocimiento Geológico del Territorio Colombiano 2014-2023 (2014) [en línea] <https://www2.sgc. gov.co/Publicaciones/Cientificas/NoSeriadas/Documents/Plan _Estrategico_2014-2023.pdf> Servicio Geológico Colombiano
(Colección Administración, Gestión y Desarrollo) [Consulta: 13/04/2018]

- TABORDA, C. (2018) El fósil que recuperó su cráneo después de 66 años. El Espectador [en línea] <https://www. elespectador.com/noticias/ciencia/el-fosil-que-recupero-sucraneo-despues-de-66-anos-articulo-748416> 5 de abril de 2018 [Consulta: 13/04/2018]

- WING, S. L.; HERRERA, F.; JARAMILLO, C. A.; GÓMEZNAVARRO, C.; WILF, P.; LABANDEIRA, C. C. (2009) Late Paleocene fossils from the Cerrejón Formation, Colombia, are the earliest record of Neotropical rainforest. Proceedings of the National Academy of Sciences, 106(44), 2009, pp. 1862718632 